\section{ADVISORY FACILITIES FOR LONG-STAY JAPANESE SENIOR TRAVELLERS IN CHIANGMAI}

\section{Prathurng Hongsranagon ${ }^{1}$}

\begin{abstract}
This paper is focused on the requirements of 63 long-stay Japanese senior travellers in Chiangmai, Thailand, regarding advisory facilities. Similar to other long stay Japanese senior travellers around the globe, these 63 senior travellers can afford to stay, in excess of one month as tourists, living off their pension fund. Their aim is to share in the daily life of locals during their stay. However, as newcomers, they must go through stages of cross-cultural adjustment during their long term stay in the province. It is recommended that Chiangmai set up advisory facilities capable of providing advice and orientation in the Japanese language to these senior travellers. This will upgrade the services offered by Thailand for long stay tourism, which is vital to its success and sustainability.
\end{abstract}

\section{Introduction}

In contrast to mass tourism, long stay tourism shifts the focus from the wellknown 4As, (accessibility, attraction, accommodation, and actors) (McIntosh, Goeldner, and Ritchie, 1995: 21-23), to language learning and cross-cultural

\footnotetext{
${ }^{1}$ Ph.d. candidate in Integrated Sciences Program, Thammasat University, Bangkok, Thailand
}

exchange between the tourists, considered to be visiting guests, and the locals, considered to be hosts. Though the period of long stay is in excess of one month (JETRO, 2002: 125 ), all long stay tourists have to come back home ultimately. It is therefore not, by all means, a kind of migration or permanent living arrangement. With such extended periods of stay, senior travellers from Scandinavian countries, from the United Kingdom, from the United States of America, as well as from Japan have become one of the key target markets for long-stay tourism. They have completed their career and family care-taking responsibilities and thus enjoy a great level of personal freedom and choice. They also have a steady income from pension funds provided by their governments. It is also expected that the elderly tourist market will greatly expand as the number of senior citizens globally is rapidly rising. This is due to population structure changes in leading industrial nations, including Japan (Population Division, 2001: xxvii-xxxi, 4849, and 286-287).

Thailand is one of the preferred destination countries for senior Japanese long-stay travellers (JETRO, 2002: 1-25). A reasonable cost of living, a good quality of life, the hospitality of the Thais, and good relations between Japan and Thailand are the factors which convince Japanese senior travellers to spend part of their retirement in Thailand.

Nevertheless, the fact that most newcomers to any foreign land need to go through the stages of cross-cultural adjustment cannot be ignored. Senior Japanese long-stay travellers are no exception. As a result, Thailand should prepare facilities for these senior travellers to assist them in coping with their new physical and social surroundings in Thailand. Subsequent to this adjustment, the 
senior travellers can naturally interact with the locals by themselves and experience the local way of living, which is the ultimate goal of long-stay tourism.

The case study of this article is Chiangmai province, which was chosen for three reasons. Firstly, Chiangmai has a long history of attracting international tourists due to its unique Lanna culture. Secondly, Chiangmai is one of the five pilot provinces for long stay tourism in Thailand. Thirdly, Chiangmai is one of the designated strategic areas for tourism development of Lanna Group Cities and the Borderline Economic Areas of Various Regions (Chouybumrung, 2004: 35-39).

As a result of an empirical study with 63 long-stay Japanese senior travellers in Chiangmai, who were members of the Chiangmai Long Stay Life Club (CLLC), located in Muang District, Chiangmai, this article recommends setting up of advisory facilities, which have the capability of providing advice in the Japanese language for long stay Japanese senior travellers in the province. The following sections of this article will examine firstly, the meaning of culture, secondly, the process of crosscultural adjustment in a foreign land by newcomers, thirdly, the research and findings of a study on 63 long-stay Japanese senior travellers in Chiangmai, fourthly, a range of possible services offered by advisory facilities for long stay Japanese senior travellers in Chiangmai, and finally, conclusions and recommendations.

\section{Culture}

Culture is defined as a negotiated set of shared symbolic systems that guide individuals' behaviors and incline them to function as a group (Chen and Starosta, 1998: 26-27; Reisinger and Turner, 2003: 5 and 12-
14; Lustig and Koester, 2003:25-31; Gudykunst, 1998:41-42; Reynolds and Valentine, 2004: xv-xvi; Landis, Bennett, and Bennett, 2004: 167-168; Dodd, 1991: 41). The functions of culture include:

Providing a context in which three aspects of human society are embedded: linguistic, physical, and psychological. Language allows us to communicate with people who have similar values and belief systems; physical aspects supply an environment of activities and permit what we do within the culture, and the psychological aspect is related to our mental activities, including what we believe and what we have learned;

Providing structure, stability, and security that are used by the group and members to maintain themselves as a healthy system.

Culture possesses the following four basic characteristics: holistic, learned, dynamic, and pervasive. Being holistic underscores the complex nature of culture whereby any change in a subsystem will have an effect on the whole system. Culture is something to be learned since it is a shared symbolic system within a relatively large group of people. The dynamic characteristic of cultures demonstrates that cultures constantly change over time with some being more open and accepting of change, while others tend to resist it. Lastly, culture is pervasive as it penetrates into every aspect of our life and it is the sum total of human society and its meanings.

\section{Cross-Cultural adjustment process}

Entering into a new culture is generally accompanied by culture shock (Chen and Starosta, 1998: 164-170; Reisinger and Turner, 2003: 56-63; Lustig and Koester, 
2003:165). Culture shock is the reaction of newcomers to problems encountered in dealings with the host members. Six common aspects of culture shock include:

A feeling of strain that comes from our attempts at psychological adjustment;

A feeling of loss regarding friends and family, social status, and possessions;

A feeling of being rejected by or rejecting the host nationals;

A feeling of confusion in beliefs, values, and role expectations;

A generalized feeling of anxiety, disgust, or surprise in the face of cultural differences;

A feeling of impotence for being unable to cope with aspects of, or tasks in, the new environment.

Effects of culture shock can be either positive or negative depending on individual personality. In the positive sense, culture shock may contribute to individual growth as it can serve as a motivational force for newcomers to move to new levels of selfactualization. It can also give them a welcome sense of challenge and achievement as a result of dealing with people from very different backgrounds. The experience from culture shock produces new ideas that, in turn, offer a new set of behavioral responses for future unfamiliar situations. On the negative side, however, culture shock constitutes an imbalancing experience which may be detrimental to the psychological growth of some newcomers. Sorting through feelings about cultural differences may take a long time or indeed may even prove impossible for some.
As change and difference are inevitable for newcomers in their encounter of the host culture, the process of adjusting to a new culture can produce a feeling of loss of cultural identity in some and stimulate personal growth for others. Newcomers experience to one degree or another four emotional and affective states in the process of cross-cultural adjustment. They are alienation, marginality, acculturation, and duality (Chen and Starosta, 1998: 171; Lustig and Koester, 2003:164-170; Landis, Bennett, and Bennett, 2004: 340-343; Dodd, 1991: 305-318). Alienation is the first state and causes a strong desire in newcomers in retaining the identification with their own culture. The rejection of the host culture leads one to limit his or her social circle to acquaintances and to seek his or her own nationals for social enjoyment. Marginality, as the second stage, often prevents newcomers from appreciating or enjoying their own culture or that of the host as they remain reluctant to relinquish the major habits and customs of own culture. Acculturation occurs when newcomers establish a strong need to adopt the way of living of the host culture. Duality is the last and successful stage of adjustment and represents the ability to accommodate both original and new host culture while living in a new environment. Such flexibility provides new skills to value cultural contrasts and to integrate new and existing beliefs and rules. The attitudes of openmindedness and flexibility are required in this situation to maintain an appropriate balance between continuity and growth.

\section{Study method and findings}

The research study reported in this paper was conducted in Chiangmai from 1-31 July 2004 with the cooperation of 63 Japanese senior travellers in order to find their needs and wants during their long-term stay in 
Chiangmai. The questionnaire was used in order to measure the respondents' level of knowledge (about long-stay tourism and about Thai culture), the level of attitudes (towards long stay tourism), and the level of requirements (during their stay in Chiangmai). Prior to the data collection, the try-out of the questionnaire with 28 Japanese in Bangkok was done in March 2004 with a satisfactory reliability value according to Cronbach's Alpha Coefficient standard.

The sample, who were both male and female of at least 60 years of age, was selected with a stratified sampling method. They were members of the Chiangmai Long Stay Life Club (CLLC). CLLC is located in Muang District, Chiangmai, and has been managed by Mr. Soichiro Kawai since 2003. In 2004, there were 108 CLLC members (51 males and 57 females). Most of the members were married couples, with a small number being single, divorced, or widowed. CLLC was established in order to welcome and facilitate Japanese senior travellers who are interested in staying long-term in the province.

From an interview session with CLLC manager, Mr. Kawai, it was found that CLLC holds bi-weekly meetings so that members can share their experiences. In fact, male CLLC members play golf twice a week, while female CLLC members gather together to do some Japanese embroidery work or some Japanese arts. It is clear that the long-stay Japanese senior travellers in Chiangmai still strongly identify with their own culture and seek their own nationals for social enjoyment. With the kind cooperation of Mr. Kawai, the respondents filled-in a copy of the questionnaire.

The data was analyzed and is presented in descriptive statistical values (frequency distribution and percentage) for the respondents' demographic data. The frequency distribution, percentage, and median value are presented in a discussion on the respondents' level of knowledge, level of attitudes, and level of requirements during their long-term stay in Chiangmai. To measure these aspects, three levels were used, namely, high equals 3 , medium equals 2 , and low equals 1 . While the high level in the measurement of knowledge and of requirements meant high, and the low level meant low, the level of high in the measurement of attitudes meant positive and the level of low meant negative on each of the corresponding items. For all statistical analysis of the data, the Statistical Package for the Social Science (SPSS) computer program was used.

\section{Demographic Data}

The 63 individuals in the sample group had an average age of 63.98 years. They had been living in Chiangmai for a period of 5.78 years on average ( $93.7 \%$ ), with frequent trips back and forth between Japan and Chiangmai. Most of them were male $(63.5 \%)$, married $(90.5 \%)$, and had bachelor's degrees (46.0\%). In the past, they used to work as state officers for the Japanese government $(25.4 \%)$. The respondents had a monthly pension of 30,833-92,499 baht (52.4 $\%$ ), and had monthly expenses of 55,00073,999 baht $(46.0 \%$ ) (when 100 yen is equivalent to 37 baht).

\section{Knowledge of the respondents}

It was found that the respondents had a high level of knowledge about long-stay tourism and about Thai culture (median 2.30) since they had been living as longstay senior travellers in Chiangmai for a period of 6 years on average. 


\section{Attitudes of the respondents}

Since spending part of their retirement in Chiangmai is their choice, the respondents possessed good attitudes towards long stay tourism $($ median $=2.26)$.

\section{Requirements of the respondents}

As shown in table 1(see appendix), the level of overall requirements expressed during the respondents' long-term stay in Chiangmai was on a medium level (median $=1.60)$. However, looking into each aspect of their requirements, namely, the physical, the emotional, and the spiritual needs of the respondents, the statistical values interestingly revealed the following: the requirements of lodging and nutrition (physical) were on a medium level (median $=1.96$ and median $=1.41$ respectively); the requirements of orientation sessions for the first 3 months of living in Thailand and on ranges of advice required (emotional) were on a high level (median $=2.20$, and median $=2.18$ respectively); and the requirement of having an opportunity to participate with the local population (spiritual) was on a high level. For instance, the respondents' requirement of having cooperation with leaders of rural villages in the suburbs of Chiangmai had a median value of 2.07, while their requirement of having such cooperation with leaders in Chiangmai town had a median value of only 1.64 , and with leaders of the urban community area had a median value of only 1.61. This may be explained by the fact that the respondents, having experienced Chiangmai for quite some time, wish to spend part of their retirement by joining with leaders of villages far from town in order to learn more about the way of life of rural Chiangmai people.

In summary, the requirements of the respondents during their long-term stay in
Chiangmai had a clear emphasis on advisory facilities to be arranged by the Thai government. The aim is for them to get the necessary consultation on a variety of issues pertaining to their daily living in the province. It is obvious that regardless of the length of time they spent in Chiangmai, the respondents would still like to be helped in successfully adjusting cross-culturally. As physical needs are basic for human beings' living, lodging and nutrition requirements are the first priority. Once satisfied, people seek emotional well-being, especially when they have to encounter changes and differences in a new cultural environment overseas. Finally, in order for them to achieve the ultimate goal of long stay tourism, the Japanese senior travellers would like to participate in cultural exchange activities with the local population, which catered for their spiritual needs. After successful cross-cultural adjustment, the long stay Japanese senior travellers are not only able to stimulate their individual personal growth and to succeed in new challenges and achievements, but also to motivate themselves to move to new levels of self-actualization.

\section{A range of possible services offered by advisory facilities for long-stay Japanese senior travellers in Chiangmai}

In comparison to the Program of "Happy Living in Tokyo", organized by the Department of Foreign Residents, Tokyo Metropolitan Government, Japan, and as a result of an empirical study with 63 long stay Japanese senior travellers in Chiangmai, it has been confirmed that in order for the Japanese senior travellers in Chiangmai to successfully go through the four-stage crosscultural adjustment process, namely, alienation, marginality, acculturation, and 
duality, it is necessary that Chiangmai, as the host city, set up advisory facilities for these senior travellers. As for the recommendation, consultations should be conducted in the Japanese language, either by Japanese-proficient personnel or by outsourcing to professional interpretation companies, in order to ensure the full understanding of the concerned parties. Consultation may be in the form of telephone consultation or face-to-face counseling. In all cases, the service should be free of charge and confidentiality must be strictly ensured. The purpose of the consultation is to make the life of the longstay Japanese senior travellers comfortable during their stay in Chiangmai and to make Chiangmai province more accessible to them. The principal contents of the consultation service should include, but are not limited to, the following areas (Tokyo Metropolitan Government, 2003: 1-70):

\section{Physical aspect:}

Information on attraction spots in Chiangmai e.g. picnic places, parks, museums, zoos, galleries, gardens, historical sites, arts centres, libraries, etc;

Information on useful telephone numbers e.g. those for the train station, airport, limousine services, government offices, hospitals and health care centres, embassies, consulates, etc., including future monorail and shuttle bus transportation services in Chiangmai;

Information on the profile of Chiangmai and Chiangmai weather conditions, provision of a map of Chiangmai, and access to Chiangmai updates (via radio or internet).

\section{Psychological aspect:}

Consultation on emergencies related to urgent personal health and safety issues such as for fire prevention and disaster prevention (i.e. earthquakes), rescue units, ambulance services, medical information, as well as crime and accident information;

Consultation on problems related to the senior traveler's daily life:

Information on relevant legal procedures such as visa procedures and police station report procedures in case of an accident;

Information on housing issues such as housing location, housing contracts, housing terms and conditions, recommendations on certified real estate, household insurance, etc;

Information on medical issues such as medical service centres, hospitals, medical insurance, etc;

Information on vehicle issues such as driving license applications, traffic law compliance, motor vehicle types, motor vehicle insurance, etc;

Information on telephone issues such as applications for a telephone land line and mobile telephones, the recent introduction of registration requirements for pre-paid mobile telephone sim cards, service charges, etc;

Information on value-added tax, duty free and consumer protection rights;

Information on postal services and communication; 
Information on financial institutions;

Information on mass transportation services;

Provision of a communication channel (via letter, facsimile, or internet) to the Chiangmai governor for the purpose of communicating proposals or requesting the execution of public works.

\section{Spiritual aspect:}

Consultation on Chiangmai customs, tradition, culture, and social systems;

Consultation on cultural exchange activities with the locals in urban community and in rural communities of Chiangmai.

\section{Conclusions and Recommendations}

Reisinger and Turner (2003:31) state that one of the most important aspects of successful international tourism development is to understand the cultural differences between international tourists and a host society. These differences are particularly related to cultural values and the needs and perceptions of international tourists and hosts. The aim of tourism marketing is thus to satisfy the needs and wants of various groups of international tourists. If the tourism products or services do not adequately satisfy international tourists' needs and fail to address adequately the cultural values of the tourist society, tourism marketers and managers must revise and/or design their product and service offerings. Since cultural elements are potential grounds for cultural misunderstanding and conflict between international tourists and locals, markets and managers must study them to recognize the differences, understand how cultural factors influence the others' behavior, and implement strategies that successfully target the particular cultural group.

From the above identification of issues and discussion it can be concluded that in order for Chiangmai to properly welcome long stay Japanese senior travellers, it is vital that Chiangmai set-up advisory facilities, which can provide consultations in the Japanese language. Long-stay tourism does not only require the normal 4As- accessibility, attraction, accommodation, and actors which are present in mass tourism. In fact, long stay tourism is in great need of the missing fifth A - advisory facilities, in order to guide the senior travellers through their cross-cultural adjustment period. This will help them accomplish their goals and objectives during their long-term stay. As long-stay visitors, Japanese senior travellers want to learn more about foreigners in-depth so that part of their retirement will become worthwhile both for themselves and for the new community they have contact with. Japanese senior travellers are well aware of the fact that long-stay tourism overseas will permit them the chance to experience local ways of living. However, before they can successfully have natural interaction with the locals, they first need to adjust themselves to their new surroundings. This is a natural and normal stage that newcomers encounter. They need to overcome the period of loss and anxiety so that they can recover their interest in the new environment and gain a better understanding of the cultural differences that initially may have caused them frustration or confusion. Only by being able to reach the stage of duality can long-stay Japanese senior travellers focus on the gains made possible by their new experiences in Chiangmai. 
By filling in the gap of this fifth A (advisory facilities) long-stay Japanese senior travellers would have access to helpful information, ranging from urgent inquiries, to daily life issues, to cultural exchange with the locals, and to general issues of interest. This would allow them to better plan their life in advance. The setting-up of advisory facilities in Chiangmai would not only be an innovation for the province and indeed Thailand itself but it would also upgrade the dedicated service offered to long-stay senior travellers in Thailand. This would help ensure the success of long-stay tourism projects in Thailand in a sustainable manner.

\section{References}

Chen, Guo-Ming, and Starosta, William, J. 1998. Foundations of Intercultural Communication. Boston: Allyn and Bacon.

Chouybumrung, Therdchai. 2004. 'One jigsaw of new tourism management'. Journal of Research Community, Vol.57, September-October 2004, pp. 35-39.

Dodd, Carley, H. 1991. Dynamics of Intercultural Communication $\left(3^{\text {rd }} \mathrm{ed}\right)$. Dubuque: Wm. C. Brown Publishers.

Gudykunst, William, B. 1998. Bridging Differences- Effective Intergroup Communication ( $3^{\text {rd }}$ ed $)$. CA: Sage Publications.

JETRO (Japan External Trade Organization). "Japanese long stay overseas." Research paper, Bangkok, October 2002.
Landis, Dan, Bennett, Janet, M., and Bennett, Milton, J. (ed.). 2004. Handbook of Intercultural Training $\left(3^{\text {rd }}\right.$ ed). CA: Sage Publications.

Lustig, Myron, W. and Koester, Jolene. 2003. Intercultural CompetenceInterpersonal Communication Across Cultures ( $4^{\text {th }}$ ed). Boston: Allyn and Bacon.

McIntosh, Robert, W., Goeldner, Charles, R. and Ritchie, Brent, J.R. 1995. Tourism: principles, practices, philosophies $\left(7^{\text {th }}\right.$ ed). New York: John Wiley \& Sons.

Population Division, Department of Economic and Social Affairs, United Nations. Report ST/ESA/SER.A/207 ISBN 92-1-051092-5. (2001).

Reisinger, Yvette, and Turner, Lindsay, W. 2003. Cross-Cultural Behaviour in Tourism - Concepts and Analysis. Oxford: Butterworth Heinemann.

Reynolds, Sana, and Valentine, Deborah. 2004. Guide to Cross-Cultural Communication. New Jersey: Pearson Education.

Tokyo Metropolitan Government. 2003. Handbook on living in Tokyo Information for Foreign Residents. Tokyo: Tokyo Metropolitan Government, Japan. 


\section{Appendix}

Table 1: Aspects and levels of requirements of the sample

\begin{tabular}{|c|c|c|c|c|}
\hline \multicolumn{5}{|c|}{ Level of requirements } \\
\hline $\begin{array}{l}\text { Aspects of } \\
\text { requirements }\end{array}$ & High & Medium & Low & Median values \\
\hline \multicolumn{5}{|l|}{ Physical } \\
\hline Lodging & $\begin{array}{c}29 \\
(46.0 \%) \\
\end{array}$ & $\begin{array}{c}21 \\
(33.3 \%) \\
\end{array}$ & $\begin{array}{c}13 \\
(20.6 \%) \\
\end{array}$ & 1.96 \\
\hline Nutrition & $\begin{array}{c}6 \\
(9.5 \%) \\
\end{array}$ & $\begin{array}{c}40 \\
(63.5 \%) \\
\end{array}$ & $\begin{array}{c}17 \\
(27.0 \%) \\
\end{array}$ & 1.41 \\
\hline \multicolumn{5}{|l|}{ Psychological } \\
\hline Orientation & $\begin{array}{c}37 \\
(58.7 \%) \\
\end{array}$ & $\begin{array}{c}16 \\
(25.4 \%) \\
\end{array}$ & $\begin{array}{c}10 \\
(15.9 \%) \\
\end{array}$ & 2.20 \\
\hline Advices & $\begin{array}{c}36 \\
(57.1 \%) \\
\end{array}$ & $\begin{array}{c}25 \\
(39.7 \%)\end{array}$ & $\begin{array}{c}2 \\
(3.2 \%)\end{array}$ & 2.18 \\
\hline Spiritual & \multicolumn{4}{|c|}{$\begin{array}{c}\text { Having cooperation with leaders of the } \\
\text { villages in Chiangmai's }\end{array}$} \\
\hline Suburb & $\begin{array}{c}32 \\
(50.8 \%) \\
\end{array}$ & $\begin{array}{c}20 \\
(31.7 \%) \\
\end{array}$ & $\begin{array}{c}11 \\
(17.5 \%) \\
\end{array}$ & 2.07 \\
\hline Town & $\begin{array}{c}15 \\
(23.8 \%) \\
\end{array}$ & $\begin{array}{c}40 \\
(63.5 \%) \\
\end{array}$ & $\begin{array}{c}8 \\
(12.7 \%) \\
\end{array}$ & 1.64 \\
\hline Urban & $\begin{array}{c}14 \\
(22.2 \%) \\
\end{array}$ & $\begin{array}{c}40 \\
(63.5 \%) \\
\end{array}$ & $\begin{array}{c}9 \\
(14.3 \%) \\
\end{array}$ & 1.61 \\
\hline $\begin{array}{c}\text { Overall } \\
\text { Overall } \\
\text { requirements }\end{array}$ & $\begin{array}{c}14 \\
(22.2 \%)\end{array}$ & $\begin{array}{c}39 \\
(61.9 \%)\end{array}$ & $\begin{array}{c}10 \\
(15.9 \%)\end{array}$ & 1.60 \\
\hline
\end{tabular}

